\title{
A RETRO-BIOMIMETIC ONE-STEP SYNTHESIS OF NATURAL ATISANIC AND BEYERANIC DITERPENOIDS
}

\author{
Olga Chetraru, Marina Grinco, Veaceslav Kulcițki, Pavel F. Vlad and Nicon Ungur* \\ Institute of Chemistry of the ASM, 3 Academiei str., MD-2028, Chişinău, Republic of Moldova \\ *E-mail: nicon.ungur@gmail.com,fax: +37322 739775; tel.: +37322 739769.
}

\begin{abstract}
An efficient retro-biomimetic procedure for the synthesis of two natural products having atisanic and beyeranic structure is reported. The readily available ent-kaurenoic acid is used as the substrate, which provides under superacidic treatment a mixture of natural ent-beyer-15-en-19-oic and ent-atis-16-en-19-oic acids. These compounds have been reported as components of medicinal plants and possess relevant biological activity. Their structure was confirmed on the basis of chemical transformations and spectral data.
\end{abstract}

Keywords: Terpenoids, biomimetic synthesis, kaurane, atisane, beyerane.

\section{Introduction}

Diterpenoids represent a large family of natural products with a broad spectrum of biological activities. Continuous work on diterpenes reveal more and more representatives of this large group to possess interesting properties. Examples are the well known atisanic and beyeranic diterpenoids. They have been known since quite a long time, but their biological activity remained still unexplored. Only recent studies revealed quite surprising data. For example the ent-beyer-15-en-19-oic acid 1 isolated from the roots of the Mexican medicinal plant Viguiera hypargyrea showed antispasmodic and antimicrobial activity in low concentrations [1]. The related ent-atis-16-en-19-oic acids 2 was shown recently to be a oviposition stimulant for the banded sunflower moth, Cochylis hospes [2]. We present in the current communication our first results on the synthesis of natural acids $\mathbf{1}$ and $\mathbf{2}$, basing on a one-step retro-biomimetic strategy.

\section{Results and discussion}

The beyeranic and atisanic diterpenoids posess a complex structure of condensed and bridged cyclic systems. Due to the complexity of these skeletons, total synthesis of these compounds proved to be quite difficult. In fact, there are only several publications relating on the total synthesis of beyeranes or atisanes. The synthetic strategies include multiple steps and the overall performance is relatively low $[3,4]$. On the other hand, partial synthesis of atisanes and beyeranes have been reported, basing on biomimetic-like transformations of other available natural products like trachylobanic acid [5] or iso-steviol [6,7]. These approaches proved to be more efficient, both from the point of view of length and overall yield. Basing on this conclusion, we have developed a semi-synthetic approach for the synthesis of above mentioned acids $\mathbf{1}$ and $\mathbf{2}$ starting from readily available [8] ent-kaurenoic acid 3. This approach is very simple, and involves a single step transformation of the substrate to the target molecules.

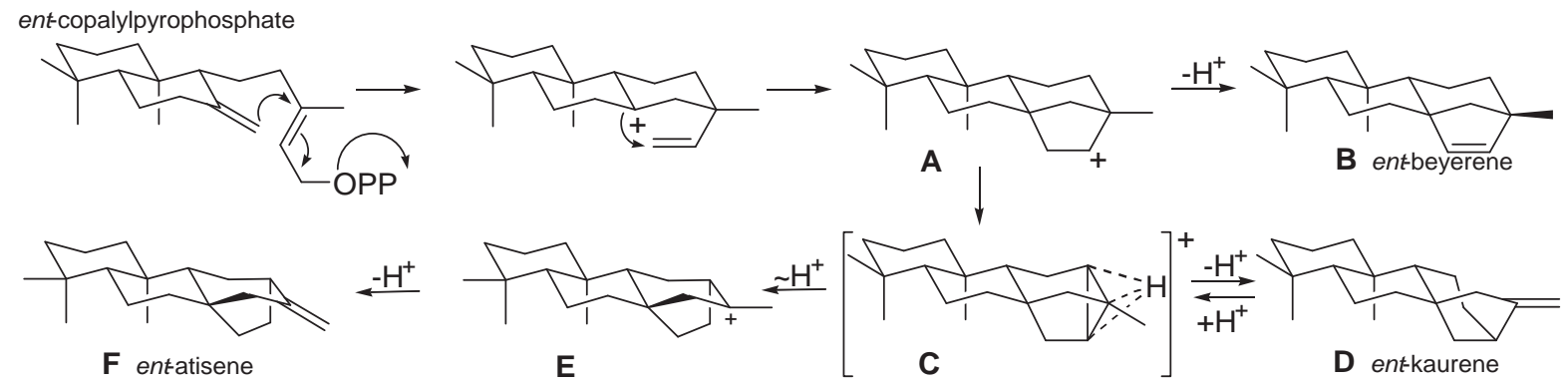

Scheme 1

The transformation is a biomimetic, acid induced rearrangement of the ent-kauranic framework to atisane and beyerane compounds. More exactly, this is a retro-biomimetic procedure, since the beyeranic framework is regarded as biogenetical precursor for ent-kauranic compounds. This hypothesis [9] has been formulated on the basis of the known isoprenic rule and to the best of our knowledge was not turned down yet. Scheme 1 provides a general overview of this biogenetical scheme, and our primarily intention was to performe the retro-biomimetic transformation of kaurene $\mathrm{D}$ to beyerene $\mathrm{B}$ or atisene $\mathrm{F}$ (path $\mathrm{D}->\mathrm{C}---\mathrm{B}$ or $\mathrm{F}$ ).

The rearrangements of ent-kauranic diterpenes has been reported under the action of different reagents [10]. Most of the examples relate on the reactions involving the formation of the non-classical carbocation of type C (Scheme 1). It is well known from the work of Olah, that superacids are better generators of these species and 
our own experience on the use of fluorosulfonic acid as an efficient promoter of terpenoids cyclization has provided a motivation to investigate the behavior of ent-kaurenic substrates under superacidic treatment. The mild reaction conditions $\left(-78^{\circ} \mathrm{C}\right)$, as well as a moderate excess of the superacid can contribute to a sufficient lifetime of generated carbonium ions so that to assure the rearrangement of ent-kaurene skeleton in a more selective manner.

Submission of the substrate 3 to this reaction condition [12] has shown that isomerisation takes place smoothly, providing a basic product, having similar chromatographical behavior as starting material. Only a small fraction of more polar byproducts was detected. The reaction pathway proved to be not sensitive to reaction conditions variation (temperature, duration, quantity of superacid).

The basic reaction product, although chromatographically homogeneous, showed a complex NMR spectrum. Analysis of silver nitrate impregnated TLC plates revealed the presence of at least 3 components, which were tentatively separated by argentation column chromatography. One pure individual compounds was isolated and its structure was determined by extensive NMR studies. The determined structure corresponded to a atisane skeleton with the exocyclic double bond 2 [13].

The mixture of acids that was considered unresolved was further separated by semi-preparative HPLC, using a normal phase column. The major isolated compound was the starting ent-kaurenic acid 3 (19\%). A minor amount $(9 \%$, on the basis of recovered 3) of beyerane $\mathbf{1}$ [14] was also obtained. Both $\mathbf{1}$ and $\mathbf{2}$ were methylated with an ethereal solution of diazomethane, to provide individual methyl esters 4 [15] and 5 [16] respectively (Scheme 2). The analytical data of the acids $\mathbf{1}$ and 2, as well as of the corresponding esters $\mathbf{5}$ and $\mathbf{6}$ matched perfectly the published data.

A minor fraction of the reaction product (cca. 30\%) was eluted in the HPLC experiment unresolved. The posibility of isolation from this fraction of individual isomerisation compounds are currently under investigation.

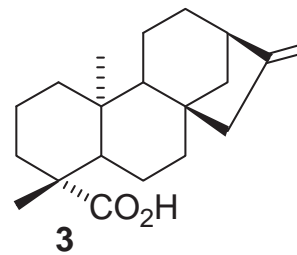

3

\section{$\mathrm{FSO}_{3} \mathrm{H}$}

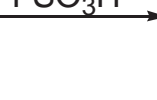$$
\text { 政 }
$$$$
1
$$

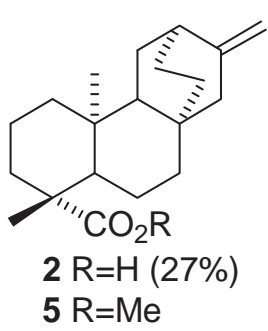

Scheme 2

\section{Conclusions}

The direct, one step conversion of ent-kaurenoic acid $\mathbf{3}$ into atisanic and beyeranic acids $\mathbf{1}$ and $\mathbf{2}$ was performed under the action of fluorosulfonic acid.

\section{Acknowledgements}

O.C. and M.G. are grateful to the Supreme Counsil for Science and Technological Development for an independent grant for young researchers (No 10.819.05.04F).

\section{References and notes}

[1]. Zamilpa, A.; Tortoreillo, J.; Navarro, V.; Delgado, G.; Alvarez, L. Planta Med., 2002, 68, 281.

[2]. Morris, B. D.; Foster, S. P.; Grugel, S.; Charlet, L. D. Journal of Chemical Ecology, 2005, $31,89$.

[3]. Toyota, M.; Wada, T.; Ihara, M. J. Org. Chem. 2000, 65, 4565.

[4]. Abad, A.; Agull, C.; Cunat, A. C.; De Alfonso Marzal, I.; Gris, A.; Navarro, I.; Ramirez de Arellano, C. Tetrahedron, 2007, 63, 1664.

[5]. Hugel, G., Lods, L.; Mellor, J. M.; Ourisson, G. Bull. Soc. Chim. France, 1965, 10, 2894.

[6]. Coates, R. M.; Bertram, E. Tetrahedron Lett., 1968, 49, 5145.

[7]. Coates, R. M.; Bertram, E. F. J. Org. Chem. 1971, 36, 2625. 7 steps from isosteviol.

[8]. Ungur, N.; Grinco, M.; Kulcițki, V.; Barba, A.; Bîzîcci, T.; Vlad, P.F. Chem. J. Mold. 2008, 4 (2), 106.

[9]. Wenkert, E. Chem. and Ind., 1955, 282.

[10]. Ungur, N. D.; Barba, A. N.; Vlad, P. F. Khim. Prirod. Soedin., 1991, (1), 3.

[11]. Hanson, J. R. Chem. and Ind. (London), 1964, 1579.

[12]. A solution of ent-kaurenoic acid $3(403 \mathrm{mg}, 1.324 \mathrm{mmol})$ in a mixture of $i$-PrNO $(2 \mathrm{ml})$ and DCM (9 ml), cooled at $-70{ }^{\circ} \mathrm{C}$, was treated with $\mathrm{FSO}_{3} \mathrm{H}(662 \mathrm{mg}, 6.623 \mathrm{mmol})$ in $i-\mathrm{PrNO}_{2}(1.4 \mathrm{ml})$, under stirring. After $15 \mathrm{~min}$., the reaction was stopped by adding a solution of $\mathrm{Et}_{3} \mathrm{~N}(4 \mathrm{ml})$ in light petroleum ether $(4 \mathrm{ml})$. The usual work up gave 
$415 \mathrm{mg}$ of a crude residue, which was submited to flash chromatography. Elution with a mixture of EtOAc in petroleum ether (2\%) gave $298 \mathrm{mg}(74 \%)$ of a TLC-homogenious reaction product.

[13]. ent-Atis-16-en-19-oic acid 2. IR (neat): 2918, 1689, 1464, 1446, 1273, $1258 \mathrm{~cm}^{-1} .{ }^{1} \mathrm{H} \mathrm{NMR}\left(400 \mathrm{MHz}, \mathrm{CDCl}_{3}\right)$ : $\delta=4.73(1 \mathrm{H}, \mathrm{bd}, \mathrm{J}=2 \mathrm{~Hz}), 4.57(1 \mathrm{H}, \mathrm{bd}, \mathrm{J}=2 \mathrm{~Hz}), 2.22(1 \mathrm{H}, \mathrm{bs}), 2.15(1 \mathrm{H}, \mathrm{bd}, \mathrm{J}=14 \mathrm{~Hz}), 2.04(1 \mathrm{H}, \mathrm{bd}, \mathrm{J}=17 \mathrm{~Hz})$, 1.29-2.00 (m, 19H), $1.25(3 \mathrm{H}, \mathrm{s}), 1.24(3 \mathrm{H}, \mathrm{s}), 0.91-1.18(\mathrm{~m}, 8 \mathrm{H}), 0.90(3 \mathrm{H}, \mathrm{s}), 0.70-0.88(\mathrm{~m}, 8 \mathrm{H}) .{ }^{13} \mathrm{C} \mathrm{NMR}$ $\left(100 \mathrm{MHz}, \mathrm{CDCl}_{3}\right): \delta=182.33$ (s, C-19), 152.77 (s, C-15), 104.52 (t, C-17), 57.17 (d, C-5), 52.21 (d, C-9), 48.21 (t, C-16), 43.70 (s, C-4), 39.73 (t, C-1), 39.66 (t, C-7), 38.40 (s, C-10), 38.08 (t, C-3), 36.61 (d, C-12), 33.55 (s, C-8), 28.90 (q, C-18), 28.73 (t, C-14), 28.32 (t, C-13), 27.27 (t, C-11), 20.27 (t, C-6), 18.76 (t, C-2), 12.10 $(\mathrm{q}, \mathrm{C}-20)$.

[14] ent-Beyer-15-en-19-oic acid 1. IR (neat): 2935, 1685, 1445, 1255, $1190 \mathrm{~cm}^{-1} .{ }^{1} \mathrm{H} \mathrm{NMR}\left(400 \mathrm{MHz}, \mathrm{CDCl}_{3}\right)$ : $\delta=5.76(1 \mathrm{H}, \mathrm{d}, \mathrm{J}=5.7 \mathrm{~Hz}), 5.47(1 \mathrm{H}, \mathrm{d}, \mathrm{J}=5.7 \mathrm{~Hz}), 1.26(3 \mathrm{H}, \mathrm{s}), 1.01(3 \mathrm{H}, \mathrm{s}), 0.69(3 \mathrm{H}, \mathrm{s}) .{ }^{13} \mathrm{C} \mathrm{NMR}(100 \mathrm{MHz}$, $\left.\mathrm{CDCl}_{3}\right): \delta=184.3$ (s, C-19), 136.5 (d, C-16), 134.8 (d, C-15), 61.1 (t, C-14), 57.2 (d, C-5), 52.4 (d, C-9), 49.2 (s, C-8), 43.9 (s, C-4), 43.7 (s, C-13), 39.6 (t, C-1), 38.0 (t, C-3), 37.7 (t, C-7), 37.7 (s, C-10), 33.2 (t, C-12), 29.1 (q, C-18), 24.9 (q, C-17), 21.6 (t, C-6), 20.5 (t, C-11), 19.3 (t, C-2), 13.8 (q, C-20).

[15]. Methyl-ent-beyer-15-en-19-oate 4. ${ }^{1} \mathrm{H}$ NMR $\left(400 \mathrm{MHz}, \mathrm{CDCl}_{3}\right): \delta=5.74(1 \mathrm{H}, \mathrm{d}, \mathrm{J}=5.7 \mathrm{~Hz}), 5.48(1 \mathrm{H}, \mathrm{d}, \mathrm{J}=5.7$ $\mathrm{Hz}), 3.60(3 \mathrm{H}, \mathrm{s}), 1.20(3 \mathrm{H}, \mathrm{s}), 1.02(3 \mathrm{H}, \mathrm{s}), 0.59(3 \mathrm{H}, \mathrm{s}) \cdot{ }^{13} \mathrm{C} \mathrm{NMR}\left(100 \mathrm{MHz}, \mathrm{CDCl}_{3}\right): \delta=178.08(\mathrm{~s}, \mathrm{C}-19)$, 134.77 (d, C-16), 136.52 (d, C-15), 61.09 (t, C-14), 57.15 (d, C-5), 51.09 (q, - CO 2 Me), 52.32 (d, C-9), 49.16 (s, C-8), 43.66 (s, C-4), 43.66 (s, C-13), 39.59 (t, C-1), 38.23 (t, C-3), 37.67 (t, C-7), 37.76 (s, C-10), 33.15 (t, C-12), 28.97 (q, C-18), 24.87 (q, C-17), 21.67 (t, C-6), 20.46 (t, C-11), 19.33 (t, C-2), 13.64 (q, C-20).

[16]. Methyl-ent-atis-16-en-19-oate 5. ${ }^{1} \mathrm{H} \mathrm{NMR}\left(400 \mathrm{MHz}, \mathrm{CDCl}_{3}\right): \delta=4.74(1 \mathrm{H}, \mathrm{bd}, \mathrm{J}=2 \mathrm{~Hz}), 4.58(1 \mathrm{H}, \mathrm{bd}, \mathrm{J}=2 \mathrm{~Hz})$, $3.66(3 \mathrm{H}, \mathrm{s}), 1.17(3 \mathrm{H}, \mathrm{s}), 0.81(3 \mathrm{H}, \mathrm{s}) .{ }^{13} \mathrm{C} \mathrm{NMR}\left(100 \mathrm{MHz}, \mathrm{CDCl}_{3}\right): \delta=177.94(\mathrm{~s}, \mathrm{C}-19), 152.77(\mathrm{~s}, \mathrm{C}-15)$, 104.50 (t, C-17), 57.25 (d, C-5), 52.19 (d, C-9), 51.03 (q, - $\mathrm{CO}_{2} \underline{\mathrm{Me}}$ ), 48.23 (t, C-16), 43.90 (s, C-4), 39.70 (t, C-1), 39.70 (t, C-7), 38.20 (s, C-10), 38.28 (t, C-3), 36.63 (d, C-12), 33.54 (s, C-8), 28.73 (q, C-18), 28.72 (t, C-14), 28.31 (t, C-13), 27.27 (t, C-11), 20.34 (t, C-6), 18.84 (t, C-2), 11.95 (q, C-20). 